\title{
DE MISS ITALIA A LA GRAN PANTALLA: MUJER Y ESPECTÁCULO EN LOS NOTICIARIOS CINEMATOGRÁFICOS DE LA POSGUERRA ITALIANA
}

\author{
FROM MISS ITALY TO THE BIG SCREEN: \\ WOMEN AND ENTERTAINMENT IN ITALIAN NEWSREELS \\ DURING POSTWAR
}

Carlota CORONADO RUIZ

Universidad Complutense de Madrid

Recibido: $25 / 11 / 2015$

Aceptado: 12/04/2016

\section{Resumen}

Los noticiarios cinematográficos tuvieron una gran influencia social a la hora de crear y difundir modelos sociales. En este artículo se analizan los estereotipos femeninos relacionados con el mundo del espectáculo más difundidos por el cine informativo italiano después de la II Guerra Mundial y hasta la llegada de la televisión. La belleza, el atractivo y la figura eran los atributos que más se subrayaban en las actrices presentes en los noticiarios cinematográficos que semanalmente se proyectaban en los cines italianos.

Palabras clave: mujer, Italia, cine, noticiarios cinematográficos.

\begin{abstract}
Newsreels had a wide social influence in creating social models. In this paper we analize the most popular female stereotypes related to the entertainment (cinema and theater) in postwar period. Beauty, attractiveness and a wonderful body were the most common attributes in the actresses appearing in Italian newsreels every week.
\end{abstract}

Keywords: women, Italy, Cinema, Newsreels. 



\section{INTRODUCCIÓN: OBJETO DE ESTUDIO}

Sophia Loren, sus caderas anchas y cintura de avispa, fue el paradigma de belleza de la Italia de la posguerra. La difusión de este tipo de mujer se lleva a cabo a través de revistas de moda, revistas femeninas, de la publicidad y del cine de ficción y no ficción. En este último, los modelos se difundieron a través de una serie de noticias sobre concursos de belleza y espectáculos. Estas informaciones cinematográficas centradas en tres ejes temáticos -concursos de belleza, cine y teatro- constituyen el objeto de análisis de este artículo. A través de un estudio cuantitativo y cualitativo de este tipo de noticias, se pretende establecer qué modelos femeninos difundieron las noticias sobre estos espectáculos, cuáles fueron los temas principales, así como las ausencias más destacadas.

La hipótesis que se plantea esta investigación estima que los estereotipos femeninos que fueron visibles en las informaciones cinematográficas italianas después de la Segunda Guerra Mundial y hasta la llegada de la televisión coinciden con modelos propios de una sociedad patriarcal y conservadora como la italiana de entonces, en los que se tiende a cosificar a la mujer y a valorarla tan sólo por su belleza. Las mujeres que protagonizan estas noticias no se valoran por sus dotes interpretativas sino por sus curvas. Éste es el mensaje que los noticiarios cinematográficos - única información audiovisual hasta la llegada de la televisión a Italia en 1954- lanzan al público femenino.

En estos años, la influencia de los noticiarios cinematográficos seguía siendo enorme entre un público en su mayoría analfabeto. Después de la caída del fascismo desapareció el noticiario Luce, instrumento propagandístico fundamental del Régimen, pero el 19 de junio de 1945 nació su sucesor: el noticiario Nuova Luce. Tuvo, sin embargo, problemas de aceptación por parte del público: recordaba demasiado al fascismo. Por ello, desaparecerá de las pantallas en $1947^{1}$. Su relevo lo tomó la Settimana Incom, un noticiario producido por una empresa privada que realizaba actividades cinematográficas durante el fascismo: Incom (Industria Cortometraggi Milano), fundada en

1. Se produjeron sólo 22 números entre 1945 y 1947.

Feminismo/s 27, junio 2016, pp. 101-120 
1938 por Sandro Pallavicini. En 1946 creó la serie de noticiarios bisemanales Settimana Incom, que se editaron hasta 1965. Además de éstos, surgen otros noticiarios producidos por empresas privadas como la Compañía Cinematográfica Astra, que realiza el noticiario Mondo Libero, del que se realizan ciento veintidós números entre 1951 y diciembre de 1953. Estos tres noticiarios han sido la base de este estudio. Los tres se encuentran en el archivo cinematográfico del Istituto Luce, uno de los fondos documentales europeos más ricos sobre cine de no ficción ${ }^{2}$.

\section{METODOLOGÍA}

Estos noticiarios cinematográficos han integrado el corpus documental de este artículo. Para su análisis, se ha aplicado una metodología basada en los estudios sobre construcción social de la realidad. Desde la antropología hasta la historia social del arte, se han establecido metodologías y líneas interpretativas para el análisis de la imagen. Entre los estudios más recientes que ubican la imagen en un contexto histórico y sociocultural con el fin de comprenderla, se encuentra la Nueva Historia Cultural. En este enfoque, la imagen se sitúa en nuevas coordenadas: las de su producción, las de su difusión, y, finalmente, las de su recepción y consumo. Se interesa muy especialmente por los usos o funciones de la imagen, la justificación histórica de temas o géneros, o las respuestas dadas por el espectador. A ello se podría añadir el estudio de los olvidados de la Historia, niños y mujeres, que apenas aparecen reflejados en fuentes escritas, y sí lo hacen, y quizá comparativamente en mayor grado, en los materiales icónicos. Así, a partir de este modelo de análisis, se elabora una metodología específica para los objetivos que aquí se han propuesto y el tipo de fuentes utilizadas. Desde luego, se considera básico en el planteamiento metodológico el estudio de la forma y el contenido de los noticiarios.

Para establecer el grado de protagonismo que tienen las noticias sobre mujer y espectáculo dentro de los noticiarios, se ha contabilizado el número de las noticias sobre este tema. Este número se ha relacionado con el total de

2. Este material documental no ha sido objeto de numerosas investigaciones, por lo que la bibliografía sobre las informaciones cinematográficas contenidas en el Archivo Luce resulta escasa. La mayor parte de los estudios se han centrado en el periodo fascista-ver Laura- y especialmente en la figura de Mussolini -ver Cardillo- entre otros. Sobre las imágenes femeninas proyectadas por los noticiarios de este archivo destacan estudios como el de Gioia, que abarca el periodo comprendido entre 1928 y 1965. El tono divulgativo, así como el escaso espacio y la amplia extensión temporal, no permiten una profundización, ni un análisis más completo. 
noticias producidas. Además, se comparan los datos numéricos relacionados con diferentes temas dentro del mundo del espectáculo para saber cuáles son las noticias más abundantes, qué temas se repiten más, qué tipo de mujer es la más difundida.

El número de noticias que se incluyó dentro de la muestra de análisis fue resultado de un criterio de selección que pretendía dar cabida al mayor número de actividades y aspectos relacionados con la mujer y el mundo del espectáculo para no limitar su tratamiento a un enfoque reducido. Por ello, se han elegido diferentes ámbitos dentro del mundo del espectáculo en los que la mujer podía estar presente: el cine, el teatro, la ópera, la danza, los concursos de belleza, etc. Los criterios tenidos en cuenta para la elección de los temas que se querían tratar están basados en la bibliografía consultada previamente ${ }^{3}$. Finalmente, las noticias seleccionadas, vistas y analizadas han sido un total de setenta y cuatro. Estas noticias, de una duración aproximada de entre uno y cuatro minutos, forman parte de noticiarios producidos entre 1945, final de la Segunda Guerra Mundial, y 1953, último año del monopolio de los noticiarios de la información audiovisual.

El análisis de contenido de los noticiarios seleccionados que se ha llevado a cabo ha tenido como base otros estudios que han abordado los noticiarios cinematográficos como fuentes documentales, y en especial, la representación de la mujer italiana en este formato ${ }^{4}$. De esta manera se ha realizado un análisis de contenido con el fin de establecer cuáles eran los estereotipos femeninos más difundidos, los temas principales de los noticiarios, así como las ausencias más destacadas.

Los resultados de esta investigación se centran en tres bloques temáticos diferentes, cada uno desarrollado en un apartado diferente. El primero desarrolla el modelo femenino difundido en las noticias sobre concursos de belleza, protagonistas de más de la mitad de las noticias analizadas. El segundo apartado está dedicado a las actrices italianas presentes en las informaciones sobre el mundo del cine. Y finalmente, el último, plantea la representación de las mujeres dedicadas a espectáculos teatrales en estos años. El denominador común en estos tres temas es el cuerpo de la mujer como objeto, sin tener en cuenta otras características, ni capacidades femeninas. El éxito para la mujer en estos campos se identifica, por tanto, con la belleza.

3. Ver Boneschi; De Giorgio, entre otros.

4. Ver Bernagozzi, Gioia entre otros. 


\section{MISS ITALIA: EL TRAMPOLÍN PARA EL CINE}

En los años cincuenta, para dar el salto a la gran pantalla, una joven italiana que soñara con triunfar como actriz, no se inscribía a una escuela de interpretación, sino a uno de los tantos concursos de belleza diseminados por toda la geografía italiana: desde Miss Italia ${ }^{5}$ a Miss Sonrisa, Miss Cine o Miss Elegancia. Se trataba de un trampolín que permitía a muchas jóvenes tener su minuto de gloria en los noticiarios de la época, principal medio de información audiovisual hasta la llegada de la televisión, y darse a conocer entre el público y las productoras de cine de la época.

Las noticias cinematográficas de la posguerra informan puntualmente sobre el desarrollo de este concurso: presenta a las candidatas de todo el país, las selecciones en las distintas regiones y ciudades, la ceremonia de entrega de premios. Entre 1946 y 1953, se editan cuarenta noticiarios sobre concursos de belleza en Italia. De éstas, veintitrés -57,5\%- están relacionadas con la elección de Miss Italia, desde las candidatas regionales, hasta las ganadoras de premios como Miss Sorriso o Miss Cinema, que se otorgan dentro del concurso de Miss Italia. Existían además otros concursos de belleza, que se desarrollaban, por lo general, en los meses de verano, y en las zonas marítimas ${ }^{6}$.

El noticiario Incom dedica veintitrés noticiarios a Miss Italia. Incom es patrocinador del evento desde 1953, por eso, no sólo difunde estas noticias, sino que hace propaganda, a través del noticiario, para que las jóvenes italianas participen en el concurso ${ }^{7}$. Otros noticiarios de la época informan sobre otros concursos de belleza, ya mencionados, pero no sobre Miss Italia. En Mondo Libero ${ }^{8}$, por ejemplo, se dedican cinco noticias a concursos de belleza como Miss Ambra o Miss Raggiodisole.

Los requisitos para ser Miss Italia son belleza y buen tipo. Así lo manifiestan los noticiarios Incom. Las imágenes presentan a las candidatas en primeros

5. En 1939 nació en Italia el concurso de belleza denominado Miss Sorriso (Miss Sonrisa). Con la guerra se interrumpió para volver en 1946 con otro nombre: Miss Italia. El primitivo concurso era fotográfico y las concursantes sólo debían mostrar su fotogenia ante las cámaras. En el nuevo concurso, las disciplinas en las que las candidatas debían mostrar su valía se ampliaron: además de belleza ante la cámara, las chicas debían saber moverse en una pasarela, mostrar gracia y dotes interpretativas.

6. Entre los títulos más conocidos estaban Miss Ambra -nombre de una crema solar Ambre Solaire-, que se concedía, no sólo a la más bella, sino también a la mejor bronceada; Miss Raggiodisole (rayo de sol), que tenía las mismas características del anterior premio; y la Regina del mare, premio a la más bella de la ciudad de Nápoles.

7. Ejemplo: Settimana Incom 00957 (17-06-1953), «Cita con Miss Italia 1953. Viaje por los lugares en los que se llevará a cabo la primera selección de las concursantes».

8. Ejemplo: Mondo Libero M046 (25-07-1952), «Bellezas en el Adriático. Concurso de belleza para Miss Rayo de Sol». 
planos o planos medios cortos para que los espectadores puedan apreciar la belleza de las jóvenes. A este tipo de planos les acompañan planos generales de las misses desfilando ante el jurado. Suelen llevar bañador, pero también visten traje de noche. En algunas ocasiones tienen que mostrar sus dotes como bailarinas o como patinadoras. Los términos que más se repiten en este tipo de noticia son «belleza», «gracia», «fascinación», «juventud»y «elegancia». Las candidatas a Miss Italia, y a otros concursos como Stella di Film (Estrella de película), deben tener todas estas características, además de belleza y figura. En algunos noticiarios también se dice que la joven más bella de Italia, «además de guapa, debe ser culta, sensible y cordial, cualidades que no se ven en un primer o un segundo vistazo» ${ }^{9}$. Sin embargo, en otros noticiarios, se insinúa todo lo contrario. «No, no mire el periódico -le dice el narrador a una candidata a Miss Italia- déjese mirar» ${ }^{10}$. Esto coincide, como indican las teorías fílmicas feministas, con el modo de representar el cuerpo femenino en el cine en general, como objeto erótico expuesto a la mirada (Colaizzi 10).

Las candidatas a Miss Italia nunca hablan a cámara o al jurado del concurso. Dejan de tener nombre para convertirse en una región o una ciudad escrita sobre una banda de tela. Se hacen continuas referencias a la belleza y al cuerpo de las candidatas. El cuerpo femenino se convierte en un espectáculo. Las medidas de las jóvenes deben ser perfectas: se crea el rito de la medida ideal. Mujeres de la organización del concurso se encargan de medir pecho, cintura y caderas de las concursantes (De Giorgio 168). Después de muchos años de hambre y carestía, en los primeros años de la posguerra, se valoraban las formas marcadas y los cuerpos exuberantes. Estos cuerpos correspondían a los deseos del imaginario masculino y femenino de la época: la opulencia era un signo barroco de la vieja Italia hambrienta y rural (De Tassis 53) Estas mujeres establecían un modelo de belleza, y marcaron una serie de cambios en los gustos estéticos y en el ideal de belleza de la época. Un ideal de belleza que no ha sido definido por la mujer, sino por el varón, resultado de una construcción del patriarcado (Carabí, Segarra 221-230).

Además de la belleza, los noticiarios cinematográficos subrayan el atractivo de las candidatas. Algunas jóvenes como Marina, de Palermo, son «morenas y picantes» -dice el narrador del Incom número 965 (1953)-. Todas son explosivas, «en ellas hay material inflamable para encender el Vesuvio en

9. Settimana Incom 01003 (14-10-1953), «Elegida Miss Piemonte».

10. Settimana Incom 00965 (03-07-1953), «Cita con Miss Italia. Travelling por los rostros de las candidatas procedentes de distintas ciudades italianas». 
todos los espectadores» ${ }^{11}$. Las referencias al sexo son continuas en estas noticias: no sólo son objetos eróticos o de deseo masculino, también ellas mismas parece que no pueden hacer otra cosa que desear el deseo (Colaizzi 10). Tanto el público como los operadores de Incom se excitan ante tanta belleza: «el objetivo de nuestra cámara ha declarado que se ha quedado sin respiración» ${ }^{12}$ - bromea el narrador del Incom número 83 (1947). Lo mismo les ocurre a los miembros del jurado: «a Falconi, se le han empañado las gafas» ${ }^{13}-$ dice el narrador de Incom.

Pero no sólo se entusiasman los operadores y el jurado, también los espectadores de los noticiarios, a quienes el narrador llama la atención continuamente. Además de dirigirse al público masculino subrayando las dotes de las candidatas a Miss Italia, crea con ellos una complicidad con una serie de bromas o comentarios: usa casi siempre los juegos de palabras y los dobles sentidos al referirse a los atributos de las mujeres. «De espaldas es muy mona-dice el narrador de Incom número 55 (1947) - ¿qué pasará cuando se gire? ${ }^{14}$.

Conseguir el título de Miss Italia era mejor que una medalla de oro en las Olimpiadas. Los noticiarios de la época insisten en la importancia de este tipo de concursos, puesto que algunos de los premios consistían en un contrato para trabajar en el cine. Como se encarga de subrayar el noticiario Incom, muchas de las jóvenes ganadoras de Miss Italia, como Silvana Mangano, Lucía Bosé, Gina Lollobrigida o Silvana Pampanini, se convirtieron en grandes estrellas de cine. También otras candidatas que no ganaron, pero que deslumbraron en el concurso como Sofía Scicolone, más conocida después como Loren, a quien el jurado de 1950 consideró «una larguirucha desproporcionada», llegaron a la gran pantalla.

El noticiario Incom resalta la importancia del título de Miss Italia, «el más deseado laurel de bella entre las bellas» ${ }^{15}$. Ganar el concurso significaba para estas jóvenes un futuro, un recurso económico y profesional que les permitiría conseguir la independencia económica y un ascenso social. Conseguían triunfar gracias a la belleza, y era en ella en la que residía su valor como

11. Settimana Incom 00071 (09-08-1947), «Pequeña crónica: perros de lujo. Muestra canina en Wembley. Elecciones de Miss Nápoles».

12. Settimana Incom 00083 (03-10-1947), «Concursos de belleza. La más bella sonrisa y la más bella italiana 1947 ».

13. Settimana Incom 00844 (25-09-1952), «Proclamada Miss Italia».

14. Settimana Incom 00055 (23-04-1947), «Pequeña crónica: Milán. Elección de Miss Milán 1947».

15. Settimana Incom 00907 (19-02-1953), «Elegida una nueva Miss. Roma: concurso de belleza. Entre el público personalidades del mundo del espectáculo, de la cultura y de la política». 
mujeres. El éxito se identifica con la belleza, una obligación para las mujeres: su misión es mantener una imagen bonita y radiante para agradar al sexo opuesto y conseguir de esta manera felicidad y fortuna (Alvarado 16).

Gracias al título de Miss Italia muchas jóvenes como Lucia Bosé pasan de ser empleadas en una pastelería de Milán, a divas del cine. «El título de Miss Italia -declara Anna Maria Bugliari, Miss Italia 1950,- es un gran pasaporte para el cine y la fama. Lo ha sido para mí como para muchas otras participantes del concurso ${ }^{16}$. El noticiario Incom repasa los nombres de actrices famosas que antes pasaron por la pasarela de Miss Italia. Así se anima a las jóvenes a participar en el concurso. La belleza y las dotes físicas eran un elemento de democracia que no tenían nada que ver con la pertenencia a una clase social, y que podían abrir las puertas de un destino imprevisto y privilegiado, a muchas chicas del pueblo (Boneschi 195). Se consigue un ascenso social rápido, el triunfo sin esfuerzos. En un periodo de calamidades, estas posibilidades evitan protestas o conflictos sociales incómodos para el poder.

La Settimana Incom número 398 (1950) ofrece información sobre el destino de las ganadoras del título de Miss. Presenta a las distintas jóvenes triunfadoras y la actividad a la que se dedican: «Miss Turín 47 escribe en varios periódicos que antes han hablado de ella. Miss Turín 48 cose las camisetas de su simple historia rota por la celebridad; Miss Lombardía 48 fue proclamada escultural, ahora es ella la que esculpe. Para una tentación de San Antonio, se inspira en sus memorias. ' $i C u a ́ l e s$ son tus proyectos, Miss Campania?' -pregunta el entrevistador-. 'Estoy prometida -responde ella-y espero casarme'» ${ }^{17}$. Además de estas jóvenes que siguen con su vida normal, el noticiario muestra a aquellas que han triunfado en el cine: «una se prepara en el gimnasio para hacer una película en la que hará de acróbata ${ }^{18}$. La noticia termina con una de las más famosas entre las Miss Italia, Silvana Mangano. La actriz está en el hospital junto a su bebé recién nacido: «Yo creo -reconoce Silvana Mangano ante las cámaras de Incom- que ésta es la mejor interpretación que he hecho, ¿no os parece? Perdonad, es la hora de la leche» ${ }^{19}$. La noticia cierra con una actriz, ex-miss, pero que ahora está cumpliendo con su verdadera misión: ser madre. Éste es en realidad el destino de muchas de estas chicas: después del éxito y la fama, la maternidad.

En este destino conservador de la mujer insisten algunos noticiarios Incom. Cuando las jóvenes concursantes piensan en otra meta diferente al

16. Settimana Incom 00954 (10-06-1953), «Buscamos a la más bella de Italia».

17. Settimana Incom 00398 (02-02-1950), «Nuestras encuestas: Destino de las Miss».

18. Settimana Incom 00398 (02-02-1950), «Nuestras encuestas: Destino de las Miss».

19. Settimana Incom 00398 (02-02-1950), «Nuestras encuestas: Destino de las Miss».

Feminismo/s 27, junio 2016, pp. 101-120 
matrimonio, el narrador de Incom lo señala: «La corona le toca a una veinteañera estudiante de derecho, enemiga del matrimonio» ${ }^{20}$. Cuando se da la enhorabuena a estas jóvenes, el presentador de la gala dice «le deseo un gran éxito y tener muchos hijos» ${ }^{21}$. Aunque no estén casadas, el noticiario recuerda que el matrimonio será su destino porque pretendientes no faltan: «Ninguna está prometida -dice el narrador de Mondo Libero 43 (1952)- pero muchos son los pretendientes» ${ }^{22}$.

Aunque con el título de Miss les llovían los contratos de cine, como señala el noticiario Incom 225 - «a Ornella Zaperetti, le llegan de todo el mundo ofertas de cine, de matrimonio, mientras, ella ha dejado el instituto y se ha inscrito en la Escuela de Cine» ${ }^{23}-$, no podían olvidar su condición de mujer y por lo tanto de madre. De hecho, se crea un concurso, del que informa el noticiario Incom, en el que no sólo se valora la belleza, sino también el ser una buena ama de casa, lo ideal para la mujer italiana.

Hay un viejo proverbio de Abruzzo que dice 'la belleza no basta si la chica no tiene las manos de oro'. En su honor, ha nacido el concurso para la mejor y más bella chica de Abruzzo. Nada de desfiles en bikini para las concursantes, sino con los tradicionales trajes de Abruzzo y Molise (...) Y en vez de la pasarela, competiciones de bordado y gastronomía. Al marido se le conquista por el estómago ${ }^{24}$.

Se pone de manifiesto que el modelo de esposa y madre ejemplar sigue vigente en la sociedad italiana de los años cincuenta. El estereotipo de mujer que representa Miss Italia es de mujer moderna, atractiva, promiscua, que se dedicará al mundo del espectáculo, mientras que la ganadora de este concurso es la mujer ideal para una sociedad tradicional como la italiana.

Ante la pregunta « ¿quién es vuestra mujer ideal?», realizada por un periódico a los jóvenes italianos, la respuesta fue Rita Hayworth. Sin embargo, cuando se definía a la verdadera mujer ideal, a aquella con la que se casarían,

20. Settimana Incom 00972 (29-07-1953), «Elegida Miss Cine de Roma. Velada mundana para la elección de Miss Cine: La Mangano, Fabrizi, Rascel y la Marzi presentes en la gala».

21. Settimana Incom 00972 (29-07-1953), «Elegida Miss Cine de Roma. Velada mundana para la elección de Miss Cine: La Mangano, Fabrizi, Rascel y la Marzi presentes en la gala».

22. Mondo Libero M043 (11-07-1952), «Bellezas en el mar. Concurso de belleza en Sorrento».

23. Settimana Incom 00225 (16-12-1948), «Bastidores de un concurso: Ornella Zamperetti contra Miss Italia».

24. Settimana Incom 00973 (30-07-1953), «La más bella y la mejor de Abruzzo. Roseto: presentación de las participantes en el concurso. Además de valorar la belleza de las candidatas, se debe premiar la habilidad en la economía doméstica». 
ésta era simple, alta, morena, sonriente, una buena chica, mejor si era graciosa, honrada, fiel, de cualquier clase social, y una futura buena madre (De Giorgio 79).

\section{CINE Y MODELOS FEMENINOS: CINTURA DE AVISPA Y CADERAS ANCHAS}

Después de las penurias de la guerra, estallaron entre los italianos las ganas de vivir. Llegaron los americanos, los blue-jeans, los cigarrillos y la música. El boogie-woogie era el baile de moda. Las salas de baile como la Sirenella de Milán se llenaban cada día. Las luces de neón rojas, blancas y azules con nombres muy cercanos al pecado y con palabras impronunciables para entonces como dancing, music-hall, night-club, llenaban las calles de las grandes ciudades. Los domingos se iba a la feria y por cinco liras las parejas subían a la noria. En Roma, los locales de moda eran el café Doney, en via Veneto, la Casina delle Rose, el café Greco, el Babbington o el Golden Gate (Innocenti 51). En todos ellos, jóvenes alocados y estraperlistas. Un aire de vitalidad soplaba por las calles de Italia. Baile, diversiones, espectáculos de variedades y cine. Por doscientas liras se podían ver las novedades que venían de Hollywood. Por cien liras, películas de reestreno. Las salas cinematográficas se llenaban con películas estadounidenses que desde hacía muchos años no llegaban a las pantallas italianas. El cine era una fábrica de sueños que ayudaba a seguir en la realidad. En 1949 se produjo el extraordinario éxito de Lo que el viento se llevó en Italia. Comenzaron así las modas americanas. Si durante el fascismo se rechazaba completamente el modelo femenino americano, ahora, Rita Hayworth, otras como Lara Turner o la rebelde Katherine Kepburn, fascinaban al público de entonces.

El cine italiano se impregnó de estos modelos americanos. Mujeres como Jean Harlow con sus vestidos de raso blanco, Joan Crawford con sus larguísimas pestañas postizas, o Marlene Dietrich con su cigarrillo con boquilla, causaron sensación en los años de la posguerra. Actrices de cine o de revista imitaban la sofisticación de estas mujeres. Las protagonistas de estos espectáculos de variedades aparecen en los noticiarios de la época luciendo vestidos lujosos, elegantes y seductores. También otras actrices de cine presentes en noticias sobre festivales de cine como el de Venecia o sobre estrenos de películas, siguen estos modelos. Sin embargo, no son sólo mujeres explosivas o femmes fatales las que forman el universo cinematográfico italiano. El cine neorrealista es protagonizado por mujeres de generosas curvas, pero de gran personalidad. Muchas de ellas, como ya se ha señalado, eran ex-Miss Italia. De belleza popular, como la Mangano arrocera o la Lollobrigida campesina, serán 
estas mujeres quienes aparecerán en los noticiarios de la posguerra, tanto en informaciones relacionadas con el cine, como en otras de sociedad.

En los primeros años de la posguerra, las noticias sobre el mundo del espectáculo son escasas porque la industria cinematográfica italiana había sufrido un fuerte golpe y tenía que salir de las ruinas. A partir de los años cincuenta el número de noticias sobre el festival de Venecia o nuevos rodajes cinematográficos aumenta. También lo hacen las relacionadas con el teatro de variedades, muy en boga en la primera década de la posguerra.

Las noticias cinematográficas más abundantes son las que informan sobre el desarrollo de la Mostra di Venezia ${ }^{25}$. En estas noticias, las actrices aparecen, por lo general, en dos momentos distintos de la jornada: por el día, en la playa; y por la noche, en los estrenos cinematográficos del festival. En la playa se recoge su lado más lúdico: toman el sol, se bañan, hacen bromas a los cámaras o colaboran con el noticiario haciendo alguna escena cómica con otros actores. Aparecen siempre en bañador, pero nunca en bikini. El narrador explica con frases breves quién es la actriz que aparece en pantalla y qué hace: «Ésta es Elena Giusti. Perfeccionará su bronceado» ${ }^{26}$, «la Ferrero descansa en una hamaca de la playa del Lido. Delia Scala en la orilla. La Merlini en agradable conversación ${ }^{27}$.

El narrador suele nombrar a las actrices más famosas, señalando la razón de su presencia en el Lido: Anna Magnani, junto a Rossellini y el productor Cocteau, «es la protagonista del filme de Rossellini, Amore» ${ }^{28}$, informa el noticiario Incom 183 (1948). Pocos planos y comentarios escuetos se dedican a otras actrices italianas como Lea Padovani o Mariella Lotti. Por lo general, estas mujeres suelen ir acompañadas, bien del director o productor del filme, bien de sus maridos: «La actriz Carla Del Poggio con Lattuada -señala el narrador, mientras las imágenes muestran a la pareja en la playa-, en pareja el baño es mejor» ${ }^{29}$. Si las actrices están casadas, el narrador insiste en ello: «De Laurentiis y también la señora De Laurentiis. De acuerdo, es también Silvana Mangano $»^{30}$.

25. Entre 1945 y 1953 se editan treinta y cuatro noticias sobre este evento cinematográfico. En un $76,4 \%$, aparecen actrices italianas. En las restantes, la atención se centra en los directores de cine o en actores.

26. Settimana Incom 00635 (23-08-1951), «Inaugurada la Muestra del Cine de Venecia».

27. Settimana Incom 00642 (18-09-1951), «Número especial de la XII Muestra Cinematográfica de Venecia».

28. Settimana Incom 00183 (26-08-19548), «IX Muestra de Venecia: huéspedes ilustres».

29. Settimana Incom 00333 (02-09-1949), «Venecia. Muestra del Cine».

30. Settimana Incom 00832 (28-08-1952), «El Festival Cinematográfico de Venecia. Actores y directores en la importante manifestación». 
Después de presentar el lado más cercano de las estrellas de cine, los noticiarios muestran el glamour y la elegancia que rodea a estas mujeres en las galas de presentación de los filmes. «Para la inauguración -dice el narrador de Mondo Libero 53 (1952) - todas las señoras endosan los vestidos más bellos» ${ }^{31}$. Las imágenes presentan este desfile de vestidos de noche, chales de pieles, vaporosas faldas con tules, y corpiños descotados ante la alfombra roja de Venecia.

Las actrices italianas, que, como señala el Incom 481 (1950), llevan «muchas maletas y muy grandes» ${ }^{32}$, no incluyen en su guardarropa pantalones. Las únicas actrices que llevan pantalones son extranjeras ${ }^{33}$. Las actrices italianas marcan las tendencias de la moda entre las espectadoras. Éstas se fijaban en el peinado, el maquillaje o el modo de vestir de las grandes divas del cine. Muchas actrices, sobre todo cuando aparecen en la playa, parece que están haciendo un reportaje de moda ante las cámaras de Incom: posan para la cámara, a veces en actitudes muy insinuantes ${ }^{34}$. El narrador no ahorra comentarios relacionados con la belleza y el erotismo de estas actrices. Se subraya siempre, como en el cine en general, la belleza, el glamour, la feminidad, la sensualidad y el vestuario (Guarinos 113).

No aparece ninguna directora de cine, por razones obvias: eran muy pocas en todo el mundo, y en Italia, ninguna. Los altos cargos de la cinematografía italiana que aparecen en estas noticias, de Cinecittà, del ENIC ${ }^{35}$, etc., son siempre hombres ${ }^{36}$. El noticiario valora a los directores por su trabajo, inteligencia y maestría: «De Sica, además de actor -dice el narrador de Incom 490 (1950)_ ha sido imprescindible para guiar los pasos de la joven actriz Pietrangeli» ${ }^{37}$. Se aprecia el contraste entre la representación de las figuras masculinas, relacionadas con la actividad y la esfera de la producción, y las femeninas, alineadas con la pasividad, la reproducción y la belleza (Colaizzi 10).

Los adjetivos que más se dedican a las actrices, tanto de cine como de teatro, son gracia y belleza: «Elena Giusti, doble Máscara de Plata por la gracia como actriz y por la elegancia $»^{38}$. No se valora su talento interpretativo, sino más bien su físico, sobre todo cuando se trata de actrices de variedades.

31. Mondo Libero M053 (29-08-1952), «La Muestra de Venecia es mayor de edad».

32. Settimana Incom 00481 (24-08-1950), «Venecia. XI Muestra de Arte Cinematográfico».

33. Settimana Incom 00330 (26-08-1949), «Venecia. Muestra del Cine».

34. Settimana Incom 00982 (25-08-1953), «La XIV Muestra de Cine de Venecia».

35. ENIC era el Ente Nazionale Industrie Cinematografiche, nacido en 1935.

36. Ejemplo: Settimana Incom 00330 (26-08-1949), «Venecia. Muestra del Cine».

37. Settimana Incom 00490 (15-09-1950), «Venecia. Clausura del Festival Cinematográfico».

38. Settimana Incom 00170 (09-07-1948), «Máscara de plata. Entrega de premios a los ganadores de la Máscara de plata». 
También en las noticias sobre rodajes de cine se hace hincapié en la belleza y atractivo de las actrices. Cuando se presenta el rodaje de Bellezze in bicicletta, la nueva película de la ex-Miss Italia, Silvana Pampanini, el narrador de Incom hace continuos guiños eróticos a los espectadores, haciendo juegos de palabras con términos ciclísticos: «Chicas como éstas nos gustaría siempre tenerlas cerca. Ésta, enguantada como Coppi, es Silvana Pampanini. A los espectadores, más que a las ciclistas, habría que decirles 'cuidado con las curvas'. (...) No tengo nada más que proponeros, señoritas -dice el narrador a las actrices-, hagamos una escapada juntos ${ }^{39}$. Antes de subir en bicicleta para empezar la secuencia, las actrices se pintan los labios mientras se miran coquetamente al espejo de mano. Más que una noticia sobre un rodaje de cine, es sobre una reunión de bellezas.

En otros rodajes con actrices como Sophia Loren o Anna Magnani el tono es menos burlón. En este tipo de informaciones se hace una sinopsis del filme que se está rodando, se cita el equipo técnico y artístico y se nombra a la actriz, a la que se dedican algunos planos ${ }^{40}$, para finalizar mostrando secuencias que se están rodando.

Actrices bellas como la Pampanini o la Lollobrigida sirven también como representantes del cine italiano ante las visitas oficiales a Cinecittà. Su función es la de dar la bienvenida a las autoridades, siempre masculinas: «Particularmente calurosa ha sido la simpatía despertada por la atómica Silvana Pampanini en el diputado Chiostergi ${ }^{41}$ - señala el narrador de Mondo Libero número 13 (1952). Aunque en este tipo de noticias, la importancia no recae en las actrices, sino en la industria del cine, algunas actrices como Silvana Pampanini son un icono del cine italiano tan reconocible para los espectadores que Mondo Libero titula la noticia «Silvana y sus señorías. Los parlamentarios en Cinecittà» ${ }^{42}$. Su función en este tipo de noticias es estética.

Además de noticias sobre estrenos de cine, las actrices italianas de estos años suelen aparecer en informaciones relacionadas con la crónica de sociedad, actos benéficos o de asistencia. Algunas noticias son totalmente banales como la visita de actrices como Silvana Pampanini al zoo de Roma ${ }^{43}$, y otras, sin embargo, tratan sobre el apoyo de algunas actrices a actos benéficos, como

39. Settimana Incom 00541 (12-01-1951), «Un giro de Italia de nuevo género».

40. Ejemplo: Mondo Libero M088 (17-04-1953), «Aida y Radamés en la pantalla».

41. Mondo Libero M013 (21-02-1952), «Silvana y sus señorías. Los parlamentarios en Cinecittà».

42. Mondo Libero M013 (21-02-1952), «Silvana y sus señorías. Los parlamentarios en Cinecittà».

43. Settimana Incom 00697 (29-12-1951), «Strenna en el zoo. Delia Scala, Nada Fiorelli y Silvana Pampanini en el jardín zoológico de Roma». 
es el caso de Anna Magnani, quien aparece en cuatro noticias relacionadas con este tipo de actividades, muy relacionadas con la ciudad de Roma, de la que es símbolo: comedores para los más pobres, fiestas benéficas, bailes a favor de la crisis del cine, etc ${ }^{44}$. La imagen que se ofrece de esta actriz es de mujer luchadora, reivindicativa, muy acorde a sus personajes en la pantalla. Un modelo que contrasta con los arquetipos femeninos más difundidos en el cine clásico americano, donde, como señala Molly Haskell, el tratamiento de las mujeres corresponde a estereotipos más tradicionales de la feminidad: son, sobre todo, objetos de deseo o adoración, sujetos pasivos, castigados si se atreven a poner en cuestión en modelo hegemónico del «ángel del hogar»(Haskell).

\section{ENTRE LENTEJUELAS Y LIGUEROS}

El tipo de mujer difundida por el cine italiano era muy distinta a la del teatro de variedades, mucho más erótica y sensual. En los espectáculos de revista y cabaret, muy de moda en estos años, junto a los cómicos de turno como Macario o Totó, había un grupo de señoritas que se llaman soubrettes. A la soubrette o vedette, la acompañaban otras bailarinas. Nombres de soubrettes como Wanda Osiris, «Wandissima», Elena Giusti, Flora Medini o Isa Barzizza se hicieron muy famosos en los primeros años de la posguerra. A estos nombres se asociaban siempre los bodys ajustados, las lentejuelas, los tacones altos y unas piernas esculturales. Estas mujeres, junto a las bailarinas de las distintas revistas, aparecen en los noticiarios de la época, pero no presentan un gran protagonismo. Las noticias suelen dar cuenta de los nuevos espectáculos de cómicos como Macario, Rascel, Ugo Tognazzi, Totò o Dapporto ${ }^{45}$. Son comedias musicales de enredos, historias de amor picantes o cómicas. Lo importante son las risas y la belleza de las bailarinas. Sólo algunas vedettes tienen tal renombre, que aparecen en el titular de las noticias: «Galantería con Wandissima» o «Flora Medini, soubrette del año» ${ }^{46}$.

Los personajes que interpretan estas mujeres son exóticos y llamativos, siguiendo con los arquetipos hegemónicos en este tipo de espectáculos: «Wanda Osiris actualiza, haciéndola extrañamente ambigua, fatal y magnética,

44. Ejemplos: Settimana Incom 00097 (21-11-1947), «En el mundo del cine. Velada para los barrios pobres»; Settimana Incom 00256 (25-02-1949), «Por nuestro cine. Manifestación en Roma».

45. Ejemplo: Settimana Incom 00361 (11-11-1949), «En el mundo de la revista: Macario ensaya. Macario celebra las bodas de plata con el escenario».

46. Settimana Incom 00724 (15-02-1952), «Galantería con Wandissima»; Settimana Incom 00913 (05-03-1953), «Flora Medini. Soubrette del año»; Settimana Incom 00703 (10-01-1952). 
la figura de la soubrette ${ }^{47}$ - añade el narrador de Incom sobre la revista protagonizada por Wanda Osiris en 1952. La bella Elena Giusti, por su parte, en la revista Dove vai se il cavallo non ce l'hai?, «se ha vestido de ídolo exótico» ${ }^{48}$.

Además de femmes fatales, también son atómicas, como la protagonista de la revista Gran Baraonda, a quien el noticiario Incom 856 (1952) se refiere como «la atómica de la revista para la primera explosión del año ${ }^{49}$, sin mencionar su nombre. Pero no sólo son mujeres eróticas vestidas con transparencias, también resultan un poco anodinas y «atontadas, las buenas soubretinas ${ }^{50}$, como afirma el narrador de Incom. Un estereotipo de mujeres bellas, pero sin nada en la cabeza. Se reproducen los modelos femeninos presentes también en el cine de la época: estereotipos monocordes y sin matices. Su físico se convierte en una elemento escenográfico, ya que se trata de personajes sin importancia narrativa: permanecen marginadas fuera de la historia, sin actuar, incluso sin hablar. Este tipo de personajes existe no para mirar, sino para que las miren; tampoco para desear, sino para que las deseen (Casetti 253). Es por ello que se subraya el físico y la vestimenta de estas artistas, como parte de un bonito decorado, también a través del tipo de plano con el que las captan los operadores de los noticiarios: detalles de las piernas de las bailarinas, panorámicas laterales de la fila de mujeres mientras alzan las piernas. Hay pocos primeros planos de estas actrices y bailarinas: interesa más el cuerpo que la belleza del rostro.

Los temas que tratan las comedias musicales de moda en estos años suelen ser superficiales: cómicas historietas de amor con final feliz. En una de las obras que presenta Incom se habla de un tema importante para la mujer, pero desde un punto de vista cómico y burlón: el voto femenino. El espectáculo protagonizado por Macario se llama «Votad por Venus»" ${ }^{51}$. Venus es una bellísima vedette, candidata a las elecciones. La política pasa a un segundo plano para dejar paso a las lentejuelas y las ligas.

El noticiario Incom registra escenas procedentes de espectáculos teatrales interpretados para las cámaras del noticiario. Las dos escenas que se editan en estos años están plagadas de tópicos sobre la relación hombre-mujer: en $\mathrm{La}$ señorita Snob, la actriz Franca Valeri cuenta a su manicura que está harta de los hombres y que se declara anti-hombres. Su manicura le dice que aunque

47. Settimana Incom 00724 (15-02-1952), «Galantería con Wandissima».

48. Settimana Incom 00684 (07-12-1951), «Dove vai se il cavallo non ce l'hai?».

49. Settimana Incom 00856 (23-10-1952), «En Milán: Gran Baraonda».

50. Settimana Incom 00684 (07-12-1951), «Dove vai se il cavallo non ce l'hai?».

51. Settimana Incom 00692 (20-12-1951), «Votate per Venere. Imágenes del espectáculo de Macario». 
los hombres no se hacen la manicura porque se comen las uñas, a ella le gusta el sexo fuerte, con músculos y anchas espaldas ${ }^{52}$. Si en esta escena cómica la mujer es el sexo débil y el hombre el que lleva las riendas, en la que interpreta Silvio Bagolini en Il medico e la cura, la actriz es simplemente el deseo carnal, la belleza y la tentación. En la escena que presenta Incom, el médico suda al ver en la camilla a una joven en ropa interior mientras se quita las medias y el liguero ${ }^{53}$.

Personajes superficiales, bellas muñecas de porcelana o eróticas mujeres fatales son los personajes que interpretan las actrices del teatro de variedades de la época. Una excepción: Anna Magnani. La actriz de Roma Città Aperta vuelve a los escenarios en una comedia musical. El modo de referirse a ella por parte del noticiario es muy distinto: «Una gran actriz vuelve sobre los escenarios del pequeño teatro de revista. Se trata de Anna Magnani $»^{54}$. En las demás actrices se destaca la belleza y el erotismo, pero en la Magnani lo que se subraya es el talento.

Poco se dice en los noticiarios del trabajo de actriz, de los esfuerzos y la gran competencia que tienen que soportar las jóvenes promesas. Tampoco hay tantas referencias al futuro como madres de las actrices, como en las noticias sobre los concursos de belleza. La única referencia al matrimonio relacionado con el trabajo como actriz es una noticia sobre Andreina Paul, que es despedida de la revista en la que trabajaba poco después de casarse: «Cuatro días después de la boda -afirma la actriz- fui despedida. Es una falta de respeto hacia mí y hacia mi contrato $»^{55}$. La noticia se cierra con una broma del cómico del espectáculo, sin darle más importancia al despido improcedente.

Durante los años de la reconstrucción, el teatro de revista tuvo una función de puro entretenimiento de masas. Se exaltaba la belleza en sí misma, a través de las bailarinas poco vestidas, del humor con doble sentido y comprensible para todos. En este tipo de teatro el modelo femenino era la mujer bella, con buen tipo, exótica y sofisticada. Mujeres muy cercanas a los modelos americanos: desde Jean Harlow a Marilyn Monroe. Las divas de la revista son la encarnación del lujo: joyas, ramos de flores, cientos de admiradores, pieles. Se las consideraba «destrozafamilias»: la lujuria las acompañaba a todas partes.

52. Settimana Incom 00703 (10-01-1952), «La Signorina Snob. Franca Valeri en su personaje radiofónico y teatral de la Señorita Snob».

53. Mondo Libero M008 (17-01-1952), «Silvio Bagolini en Il medico e la cura. El cómico en el papel de médico «distraido» por el encanto de una paciente».

54. Settimana Incom 00976 (07-08-1953), «Cita con el teatro de revista».

55. Settimana Incom 00699 (04-01-1952), «Bailes y riñas en el mundo de la revista».

Feminismo/s 27, junio 2016, pp. 101-120 
En el cine de ficción había otros modelos distintos a los de la revista. La signora in nero (señora de negro), que se movía en ambientes macabros o delictivos, era la mujer del cine negro americano: mala, capaz de cometer las mayores atrocidades, pero el público de entonces prefería a personajes como los de Gina Lollobrigida. Además, eran más cercanas a los espectadores de entonces: sus personajes no dormían en sábanas de seda, ni tenían chófer o champagne en la nevera. En el cine italiano entraron personajes que nada tenían que ver con estas sofisticadas mujeres. Eran mondadoras de arroz, prostitutas, madres de hijos ilegítimos o mujeres de la Resistencia.

\section{CONCLUSIONES}

Mujeres como Silvana Mangano, Gina Lollobrigida, Sophia Loren o algunas de las protagonistas de las noticias sobre concursos de belleza o espectáculos de variedades, se convirtieron en iconos de la generación de los cincuenta. Las noticias sobre el mundo del espectáculo analizadas -setenta y cuatro- y las centradas en concursos de belleza -cuarenta- presentan este tipo de mujer. A diferencia de las informaciones sobre los concursos de belleza, las noticias sobre cine en las que aparecen actrices, no tienen a éstas como protagonistas. Su presencia se reduce a unos planos de breve duración: las actrices se encuentran en los estrenos de películas, en rodajes o en festivales de cine. El narrador las nombra, hace algún comentario entre frívolo y gracioso, o informa sobre lo que la actriz está haciendo en ese momento.

La misma estructura se observa en las noticias relacionadas con el mundo del teatro. En la posguerra triunfó la revista en los teatros, donde el papel de las actrices se reducía a enseñar las piernas. Del total de noticias analizadas sobre espectáculos (cine y teatro), veintitrés tienen como objeto el teatro de variedades $-31 \%$. No hay cabida en el noticiario para el teatro clásico o la ópera, espectáculos más elitistas, que difícilmente encuadran en un medio tan popular como el noticiario cinematográfico. Las actrices son en realidad vedettes que cantan y bailan: aparecen en los noticiarios de la posguerra como bellezas.

Los modelos femeninos que presentaban los noticiarios en informaciones sobre espectáculos o concursos de belleza eran muy distantes a los modelos sociales que imperaban en la Italia de la posguerra. Las espectadoras podían soñar con sedas y lentejuelas, pero sus piernas difícilmente endosarían un liguero. Este tipo de espectáculos, así como los concursos de belleza, resultaban escandalosos para los más conservadores, para quienes, además de inmorales, eran manifestaciones de un «paganismo astuto y salvaje» (Boneschi 197). En 1954, trece diputados democristianos pidieron la abolición por 
ley de los concursos de belleza. A revistas católicas como Famiglia Cristiana tampoco le gustaban: los consideraban una puesta en escena de la más pecaminosa concepción hedonista de la vida, doble pecado de promiscuidad y falta de pudor (Marazziti 112). Los comunistas no se manifestaban contra estos concursos. Consideraban que la elección de la más bella permitía la afirmación democrática de las dotes de chicas anónimas cuya gracia terminaba por imponerse en toda Italia (De Giorgio 47). Sin embargo, con los años, se imponía cada vez más la desnudez, lo que se consideraba una trampa para el honor de las candidatas.

A pesar de las críticas, Miss Italia se convirtió a final de los años cuarenta y primeros años cincuenta, en uno de los ritos sociales más emblemáticos de la posguerra. Aunque algunos lo consideraban escandaloso, para muchos era mejor que la mujer se ganara la vida más por su belleza que por su trabajo o su inteligencia. Así lo recordaba el manual de buenas costumbres de Elisabetta Randi: «Hoy la mujer trabaja como los hombres, es verdad, pero por esto no debe perder su feminidad. Recordad que lo que más se aprecia en una mujer no es la inteligencia, ni la cultura, sino la compostura exterior» (67).

Y la belleza es también la característica que más se subraya en las actrices presentes en los noticiarios, aunque no haya tanto espacio para el erotismo y la desnudez. Frente a la falta de pudor que había en algunas revistas musicales, en la publicidad o el cine, la censura se imponía. En las fotografías o carteles publicitarios no podía haber una curva excesivamente marcada; los anuncios de medias sólo podían mostrar la pierna desde la rodilla hacia abajo; y en las películas las mujeres descarriadas terminaban en la cuneta o entrando en un convento. La mayor parte de los personajes femeninos terminaban en el altar, así como las actrices que los protagonizaban. Pasaron de las pasarelas de Miss Italia a llenar celuloide para dejarlo todo por el deseado «sí quiero».

Después de la conciencia feminista y los nuevos roles adquiridos durante la Segunda Guerra Mundial, en los años cincuenta se produce una vuelta a lo tradicional: las mujeres italianas aceptan que la guerra ha sido simplemente un paréntesis y se borran las conquistas conseguidas. El cine de ficción, así como el informativo, contribuye a esta vuelta a la «normalidad»: la mujer sigue siendo servidora y esclava romántica, capaz de dejar todo por un hombre. 


\section{REFERENCIAS BIBLIOGRÁFICAS}

Alvarado Steller, Valerie y Kristel Sancho Bermúdez. «La belleza del cuerpo femenino». Revista Wímb Lu 6.1 (2011): 9-21.

Bernagozzi, Giampaolo. Il mito dell'immagine. L'immagine del mito. Bolonia: Editrice Clueb, 1983.

Boneschi, Marta. Santa Pazienza. La storia delle donne italiane dal dopoguerra a oggi. Milán: Mondadori, 1998.

Carabí, Angels y Marta Segarra Montaner. Belleza escrita en femenino. Barcelona: Centre Dona i Literatura, 1998.

Cardillo, Massimo. Il duce in moviola: politica e divismo nei cinegiornali e documentari «Luce». Bari: Dedalo, 1983.

Casetti, Francesco. Teorías del cine, 1945-1990. Madrid: Cátedra, 1994.

Colaizzi, Giulia. «El acto cinematográfico: género y texto fílmico». Lectora: revista de dones i textualitat 7 (2001): 1-10.

De Giorgio, Michela. Le italiane dall'Unità a oggi. Modelli culturali e comportamenti sociali. Roma: Laterza, 1992.

De Tassis, Piera. «Corpi recuperati per il proprio sguardo. Cinema e immaginario negli anni '50». Memoria 6 (1982): 24-31.

Gioia, Annabella. Donne senza qualità. Immagini femminili nell'Archivio storico dell'Istituto Luce: Immagini femminili nell'Archivio storico dell'Istituto Luce. Roma: FrancoAngeli, 2010.

Guarinos, Virginia. «Mujer y cine». Los medios de comunicación con mirada de género. Eds. Felicidad Loscertales Abril y Trinidad Núñez Domínguez. Sevilla: Instituto Andaluz de la Mujer: Consejería para la Igualdad y Bienestar Social, 2008, 103-120.

Haskell, Molly. From reverence to rape: The treatment of women in the movies. New York: Holt, Rinehart and Winston, 1974.

Innocenti, Marco. LItalia del dopoguerra 1946-1960. Come eravamo negli anni dal boggie-woogi alla dolce vita. Milán: Mursia, 1995.

Laura, Ernesto G. Le stagioni dell'aquila: storia dell'Istituto Luce. Roma: Ente dello spettacolo, 2000

Marazziti, Mario. «Cultura di massa e valori cattolici: il modelli di Famiglia Cristiana». Pio XII. Ed. Andrea Riccardi. Bari-Roma: Laterza, 1984, 303-334.

Randi, Elisabetta. Nozioni d'igiene per le scuole di Magistero professionale per la donna: con illustrazioni. Florencia: Marzocco, 1950. 